\title{
PENGARUH LATIHAN RENTANG GERAK SENDI EKTREMITAS BAWAH TERHADAP KESEIMBANGAN TUBUH LANSIA DI BPPLU PAGAR DEWA PROVINSI BENGKULU
}

\section{The Effect of Range of Motion of Lower Limb Joints on Body Balance in Elderly People in BPPLU Pagar Dewa Bengkulu Province}

\author{
Loren Juksen $^{1}$, Arianto Saputra ${ }^{1}$, S. Effendi ${ }^{2}$ \\ ${ }^{1}$ Program Studi Ilmu Keperawatan STIKES Tri Mandiri Sakti Bengkulu \\ ${ }^{2}$ Program Studi Kesehatan Masyarakat STIKES Tri Mandiri Sakti Bengkulu \\ Email: Juksenloren212@gmail.com
}

\section{ARTICLE HISTORY}

Received[19Agustus 2020]

Revised [06 Agustus2020]

Accepted [28 Agustus2020]

KATA KUNCI:

keseimbangan tubuh, lansia, rentang gerak

\section{KEYWORDS:}

body balance, elderly, range of motion
ABSTRAK

Lansia mengalami penurunan susunan otot sehingga penurunan kekuatan dan kontraksi otot, elastisitas, dan fleksibilitas otot, serta kecepatan dan waktu reaksi. Penelitian ini bertujuan untuk mempelajari pengaruh latihan rentang gerak sendi ektremitas bawah terhadap keseimbangan tubuh lansia di BPPLU Pagar Dewa Provinsi Bengkulu. Desain yang digunakan dalam penelitian ini adalah desain Pre Eksperimental menggunakan The One Group Pretest Postest Design. Populasi dalam penelitian ini adalah seluruh lansia di BPPLU Pagar Dewa Provinsi Bengkulu sebanyak 59 orang. Pengambilan sampel dalam penelitian ini menggunakan teknik purposive sampling sebanyak 32 orang. Penelitian ini menggunakan data primer yang didapat menggunakan alat ukur yaitu kuesioner Berg Balance scale (BBS). Analisis data dilakukan secara univariat dan bivariat. Hasil penelitian didapatkan dari 32 orang sebelum latihan rentang gerak sendi ektremitas bawah terdapat 2 orang (6,2\%) dengan resiko jatuh tinggi, 29 orang $(90,6 \%)$ dengan resiko jatuh sedang dan 1 orang $(3,1 \%)$ dengan resiko jatuh rendah, dari 32 orang setelah latihan rentang gerak sendi ektremitas bawah terdapat 17 orang $(53,1 \%)$ dengan resiko jatuh sedang dan 15 orang (46,9\%) dengan resiko jatuh rendah. Ada pengaruh latihan rentang gerak sendi ektremitas bawah terhadap keseimbangan tubuh lansia di BPPLU Pagar Dewa Provinsi Bengkulu. Diharapkan tenaga kesehatan dapat memberikan konseling, informasi dan edukasi mengenai latihan rentang gerak sendi ekstremitas bawah.

\section{ABSTRACT}

The elderly have decreased muscle structure resulting in decreased muscle strength and contraction, muscle elasticity and flexibility, as well as reaction time and speed. This study aims to study The Effect of Range of Motion of Lower Limb Joints on Body Balance in Elderly People in BPPLU Pagar Dewa Bengkulu. The design of this study used Pre Experimental research design using The One Group Pretest Postest Design. The population in this study were all elderly in BPPLU Pagar Dewa Bengkulu Province as many as 59 people. Sampling in this study used a purposive sampling technique of 32 people. This study used primary data that was obtained by measuring instrument namely the Berg Balance Scale (BBS) questionnaire. Data analysis was performed univariately and bivariately the results were obtained: (1) from 32 persons before the lower extremity range of motion exercises there were 2 persons (6.2\%) with a high risk of falling, 29 persons (90.6\%) with a moderate risk of falling and 1 person $(3.1 \%)$ with a low risk of falling;

(2) from 32 persons after lower extremity range of motion exercises there were 17 persons (53.1\%) with a moderate risk of falling and 15 
persons (46.9\%) with a low risk of falling; (3) there is Effect of Range of Motion of Lower Limb Joints on Body Balance in Elderly People in BPPLU Pagar Dewa Bengkulu. It is hoped that health worked can provide counseling, information and education about lower limb joint range of motion exercise.

\section{Pendahuluan}

Peningkatan usia harapan hidup merupakan salah satu indikasi kemajuan pembangunan kesehatan menuju Indonesia sehat. Menurut WHO (2015) lanjut usia (lansia) adalah kelompok penduduk yang berumur 60 tahun atau lebih. Secara global pada tahun 2013 proporsi dari populasi penduduk berusia lebih dari 60 tahun adalah $11,7 \%$ dari total populasi dunia dan diperkirakan jumlah tersebut akan terus meningkat seiring dengan peningkatan usia harapan hidup (Ramlis, 2018)

Indonesia termasuk negara yang akan masuk ke penduduk struktur tua, karena persentase penduduk lanjut usia (lansia) yang telah mencapai $7,6 \%$ dari total penduduk dan diproyeksikan akan terus meningkat pada tahun 2020-2035 seiring dengan Usia Harapan Hidup (UHH) Indonesia yang diproyeksikan akan terus meningkat dari 69,8 tahun (2010) menjadi 72,4 pada tahun 2035 (Kemenkes RI, 2018).

Berdasarkan proyeksi di Provinsi Bengkulu, pada tahun 2020, jumlah lansia diperkirakan akan mencapai 4,8 juta jiwa dan akan terus meningkat mencapai 9,8 juta jiwa, pada tahun 2035. Berdasarkan hasil penghitungan dan proyeksi pada tahun 2020, jumlah penduduk lansia di Bengkulu akan mencapai 260.000 jiwa (Lestari \& Hartati, 2016).

Menjadi tua adalah suatu proses natural dan kadang- kadang tidak nampak mencolok, penuan akan terjadi disemua sistem akan mengalami kemunduran pada waktu yang sama. Pada lanjut usia telah terjadi kemunduran fisik pada organ tubuh. Ada beberapa hal yang perlu diperhatikan agar tetap sehat di usia lanjut yaitu dengan memperhatikan faktor gizi dan olahraga. Dengan semakin meningkatnya usia, maka sudah jelas kesegaran jasmani akan turun. Penurunan kemampuan akan semakin terlihat setelah usia 40 Tahun, sehingga saat lanjut usia, kemampuan akan turun antara 30-50\% (Maryam, 2011)

Terdapat berbagai perubahan yang berkaitan dengan perubahan usia yang dapat mempengaruhi insiden jatuh lansia, terutama ketika perubahan tersebut berefek pada kemampuan fungsional dan menimbulkan gangguan sensori atau gaya berjalan dan ketidakstabilan keseimbangan (Lueckenotte, 2009)

Tujuan utama perawatan kesehatan lansia adalah mempertahankan lansia untuk dapat mandiri dalam sebuah lingkungan yang aman. Salah satu masalah keperawatan adalah mencegah terjadinya kecelakaan, cedera, atau trauma lain dan mencegah meluasnya infeksi, serta mempertahankan mekanika tubuh yang baik serta mencegah dan memperbaiki deformitas (Perry \& Potter, 2010).

Lansia mengalami penurunan susunan otot sehingga penurunan kekuatan dan kontraksi otot, elastisitas, dan fleksibilitas otot, serta kecepatan dan waktu reaksi. Penurunan fungsi dan penurunan kekuatan otot akan menyebabkan penurunan kemampuan mempertahankan keseimbangan postural atau keseimbangan tubuh pada lansia sehingga meningkatkan resiko jatuh pada lansia (Stocklager, 2008)

Salah satu solusi tahap awal adalah melatih pergerakan otot (range of motion) pada ekstermitas, selain itu latihan range of motion dapat mencegah terjadinya atropi otot, meningkatkan peredaran darah ke ekstremitas, 
mengurangi kelumpuhan vaskcular, memberikan kenyamanan dan juga dapat menghindari adanya komplikasi akibat kurang gerak seperti kontraktur dan kekakuan sendi (Pongantung, Sampa, \& Melchi, 2018).

Latihan gerak secara aktif dapat meningkatkan interaksi antara cortex cerebri, basal ganglia, brain stem dan cerebellum yang berperan penting terhadap perkembangan kemampuan motorik dan pengaturan gerak. Latihan gerak yang melibatkan bagian tubuh yang sakit dan bersifat repetitif akan membantu pasien pasca stroke untuk memperoleh kekuatan otot, pergerakan sendi juga memperbaiki keseimbangan (Pongantung, Sampa, \& Melchi, 2018)

Menurut penelitian Fitriyansyah, Susanto, \& Rasni (2014) yang meneliti tentang pengaruh latihan rentang gerak ekstremitas bawah terhadap keseimbangan tubuh lansia di Posyandu Alamanda 99 Kelurahan Jember Lor Kabupaten Jember. Disimpulkan bahwa terdapat pengaruh yang signifikan antara latihan rentang gerak ekstremitas bawah terhadap keseimbangan tubuh lansia di Posyandu Alamanda 99 Kelurahan Jember Lor Kabupaten Jember.

Berdasakan data Balai Pelayanan dan Penyantunan Lanjut Usia (BPPLU) Pagar Dewa Provinsi Bengkulu didapatkan pada tahun 2018 jumlah lanjut usia sebanyak 59 orang yang terdiri dari 32 orang laki-laki dan 27 orang perempuan dan terdapat 44 orang lansia yang mengalami gangguan sendi.
Sehingga mempengaruhi kesimbangan lansia dan menigkatkan resiko jatuh pada lansia.

Rumusan masalah penelitian adalah "Apakah ada pengaruh latihan rentang gerak sendi ektremitas bawah terhadap keseimbangan tubuh lansia di BPPLU Pagar Dewa Provinsi Bengkulu?. Tujuan penelitian untuk mempelajari pengaruh latihan rentang gerak sendi ektremitas bawah terhadap keseimbangan tubuh lansia di BPPLU Pagar Dewa Provinsi Bengkulu.

\section{Metode Penelitian}

Desain yang digunakan dalam penelitian ini adalah desain Pre Eksperimental menggunakan The One Group Pretest Postest Design. Populasi dalam penelitian ini adalah seluruh lansia di BPPLU Pagar Dewa Provinsi Bengkulu sebanyak 59 orang. Pengambilan sampel dalam penelitian ini menggunakan teknik purposive sampling sebanyak 32 orang. Penelitian ini menggunakan data primer yang didapat menggunakan alat ukur yaitu kuesioner Berg Balance scale (BBS). Analisis data dilakukan secara univariat dan bivariat.

\section{Hasil Penelitian \\ 1. Analisis Univariat}

Analisis univariat dilakukan untuk memperoleh gambaran keseimbangan tubuh lansia sebelum dan setelah latihan rentang gerak sendi ektremitas bawah di BPPLU Pagar Dewa Provinsi Bengkulu.

Tabel 1

Distribusi Frekuensi Keseimbangan Tubuh Lansia Sebelum Latihan Rentang Gerak Sendi Ektremitas bawah di BPPLU Pagar Dewa Provinsi Bengkulu

\begin{tabular}{cccc} 
No. & Keseimbangan Tubuh & Frekuensi & Persentase (\%) \\
\hline 1 & Resiko jatuh tinggi & 2 & 6,2 \\
2 & Resiko jatuh sedang & 29 & 90,6 \\
3 & Resiko jatuh rendah & 1 & 3,1 \\
\hline & Jumlah & 32 & 100,0 \\
\hline
\end{tabular}


Berdasarkan Tabel 1, dari 32 orang sebelum latihan rentang gerak sendi ektremitas bawah terdapat 2 orang $(6,2 \%)$ dengan resiko jatuh tinggi, 29 orang $(90,6 \%)$ dengan resiko jatuh sedang dan 1 orang $(3,1 \%)$ dengan resiko jatuh rendah.

Tabel 2.

Gambaran Keseimbangan Tubuh Lansia Setelah Latihan Rentang Gerak Sendi Ektremitas Bawah di BPPLU Pagar Dewa Provinsi Bengkulu

\begin{tabular}{cccc}
\hline No. & Keseimbangan Tubuh & Frekuensi & Persentase (\%) \\
\hline 1 & Resiko jatuh sedang & 17 & 53,1 \\
2 & Resiko jatuh rendah & 15 & 46,9 \\
\hline & Jumlah & 32 & 100,00 \\
\hline
\end{tabular}

Berdasarkan Tabel 2, dari 32 orang dari 32 orang setelah latihan rentang gerak sendi ekstremitas bawah terdapat 17 orang (53\%) dengan resiko jatuh sedang dan 15 orang $(46,9 \%)$ dengan resiko jatuh rendah.

\section{Uji Normalitas Data}

Uji kenormalan data dalam penelitian ini Data dalam penelitian ini menggunakan uji Shapiro-wilk untuk masing-masing data variabel.

Tabel 3.

Uji Normalitas Keseimbangan Tubuh Lansia Sebelum Dan Setelah Latihan Rentang Gerak Sendi Ektremitas Bawah di BPPLU Pagar Dewa Provinsi Bengkulu

\begin{tabular}{ccc}
\hline Variabel & $\mathrm{p}$ & Keterangan \\
\hline Keseimbangan tubuh sebelum latihan & 0,370 & Data berdistribusi normal \\
Keseimbangan tubuh sebelum latihan & 0,439 & Data berdistribusi normal \\
\hline
\end{tabular}

Berdasarkan hasil uji normalitas, pada keseimbangan tubuh lansia sebelum latihan rentang gerak sendi ektremitas bawah didapat nilai $p=0,370>0,05$, maka dapat disimpulkan bahwa keseimbangan tubuh lansia sebelum latihan rentang gerak sendi ektremitas bawah berdistribusi normal. Berdasarkan hasil uji normalitas, pada keseimbangan tubuh lansia setelah latihan rentang gerak sendi ektremitas bawah didapat nilai $p=$ $0,439>0,05$, maka dapat disimpulkan bahwa keseimbangan tubuh lansia setelah latihan rentang gerak sendi ektremitas bawah berdistribusi normal.

\section{Analisis Bivariat}

Analisis bivariat digunakan untuk mengetahui pengaruh latihan rentang gerak sendi ektremitas bawah terhadap keseimbangan tubuh lansia di BPPLU Pagar Dewa Provinsi Bengkulu. dengan hasil sebagai berikut:

Tabel 4.

Pengaruh Latihan Rentang Gerak Sendi Ektremitas Bawah terhadap Keseimbangan Tubuh Lansia di BPPLU Pagar Dewa Provinsi Bengkulu

\begin{tabular}{|c|c|c|c|c|c|c|c|c|}
\hline & \multicolumn{5}{|c|}{ Paired Differences } & \multirow{3}{*}{$T$} & \multirow{3}{*}{$D f$} & \multirow{3}{*}{$p$} \\
\hline & \multirow[t]{2}{*}{ Mean } & \multirow{2}{*}{$\begin{array}{l}\text { Std. } \\
\text { Dev. }\end{array}$} & \multirow{2}{*}{$\begin{array}{l}\text { Std. } \\
\text { Error } \\
\text { Mean }\end{array}$} & \multicolumn{2}{|c|}{$\begin{array}{l}\text { 95\% Confidence } \\
\text { Interval of The } \\
\text { Difference }\end{array}$} & & & \\
\hline & & & & Lower & Upper & & & \\
\hline Pretest-Postest & $-9,656$ & 7,627 & 1.348 & -12.406 & $-6,906$ & $-7,162$ & 31 & 0,000 \\
\hline
\end{tabular}


Berdasarkan tabel di atas didapat nilai mean $-9,656$ bernilai negatif, artinya terdapat kecenderungan peningkatan keseimbangan tubuh lansia setelah latihan rentang gerak sendi ektremitas bawah dengan rata-rata peningkatan 9,656. Hasil uji dua sampel berhubungan (Paired sample $t$-test) didapat nilai $\mathrm{t}=7,162$ dengan $\mathrm{p}=0,000<0,05$ berarti signifikan, sehingga Ho ditolak dan $\mathrm{Ha}$ diterima. Kesimpulan ada pengaruh latihan rentang gerak sendi ektremitas bawah terhadap keseimbangan tubuh lansia di BPPLU Pagar Dewa Provinsi Bengkulu.

\section{Pembahasan}

Berdasarkan hasil penelitian dari 32 orang sebelum latihan rentang gerak sendi ektremitas bawah terdapat 2 orang $(6,2 \%)$ dengan resiko jatuh tinggi, yaitu pada Tn. N usia 78 dengan keluhan penyakit hipertensi disertai dengan reumatik dan Ny. M usia 70 tahun dengan keluhan penyakit reumatik. Pada kedua responden ini mengalami resiko jatuh tinggi karena adanya keluhan nyeri pada lutut akibat peradangan dari rematik yang dideritanya sejak lama. Selain itu faktor usia juga mempengaruhi penurunan kekuatan otot dan rentang gerak sendi sehingga mempengaruhi kesimbangan tubuh saat berdiri ataupun berjalan.

Selain itu hasil penelitian menunjukkan terdapat 29 orang $(90,6 \%)$ dengan resiko jatuh sedang dan 1 orang $(3,1 \%)$ dengan resiko jatuh rendah. Hasil penelitian ini menunjukkan bahwa lansia memiliki keseimbangan tubuh yang beragam dan sebagiain basar dengan resiko jatuh sedang. Resiko jatuh sedang dapat berkaitan dengan karakteristik lansia yang memiliki usia $>60$ tahun. Usia 60 tahun termasuk dalam tingkatan usia yang mengalami penurunan kemampuan mempertahankan keseimbangan tubuh. Selain itu faktor aktifitas juga mempengaruhi kondisi penurunan kemampuan mempertahankan keseimbangan tubuh, sebagian besar lansia memiliki tingkat aktifitas yang kurang dalam menggerakkan anggota tubuh sehingga dapat meningkatkan penurunan fungsi ekstremitas seperti atrofi otot, pelumasan sendi berkurang, kekakuan sendi, dan penurunan fungsi saraf pada ekstremitas lansia.

Menurut penelitian Susilo, Limyati, \& Gunawan (2017) yang melakukan penelitian tentang risiko jatuh pada lansia meningkat dengan bertambahnya usia. Didapatkan hasil bahwa $48 \%$ lansia dalam kategori normal, $52 \%$ lansia dalam kategori cukup. Pada kategori Normal sebanyak 39\% dari usia 60-69 tahun dan sebanyak 9\% dari usia 70-79 tahun. Pada kategori Cukup sebanyak $17 \%$ dari usia 60-69 tahun, sebanyak 35\% dari usia 70-79 tahun. Hal ini menunjukkan usia 60-69 tahun memiliki persentase terbesar dalam kategori normal, usia 70-79 tahun memiliki persentase terbesar dalam kategori cukup.

Menurut Maryam (2011), menjadi tua adalah suatu proses natural dan kadang- kadang tidak nampak mencolok, penuan akan terjadi disemua sistem akan mengalami kemunduran pada waktu yang sama. Pada lanjut usia telah terjadi kemunduran fisik pada organ tubuh. Dengan semakin meningkatnya usia, maka sudah jelas kesegaran jasmani akan turun. Penurunan kemampuan akan semakin terlihat setelah usia 40 Tahun, sehingga saat lanjut usia, kemampuan akan turun antara 30-50\%.

Menurut Perry \& Potter, (2010), kehilangan massa tulang yang progresif terjadi pada lansia. Beberapa penyebab kehilangan ini meliputi menurunnya aktivitas sosial, perubahan hormon dan reabsorpsi tulang. Efek kehilangan ini pada tulang adalah tulang menjadi lebih lemah dan koordinasi berkurang. Menurut Lueckenotte (2009) terdapat berbagai perubahan yang berkaitan dengan perubahan usia yang dapat mempengaruhi insiden jatuh lansia, terutama ketika perubahan tersebut berefek pada kemampuan fungsional dan menimbulkan 
gangguan sensori atau gaya berjalan dan ketidakstabilan keseimbangan

Mengingat pada kondisi masingmasing lansia mempunyai kemampuan berbeda-beda serta penyakit degeneratif (penuaan), memungkinkan lansia berpotensi mengidap penyakit lebih dari satu jenis penyakit. Fenomena yang terjadi pada lansia yang tinggal di panti ditemukan masalah gangguan mobilitas fisik yang berhubungan dengan penurunan kekuatan otot. Dalam penelitian ini seluruh sampel adalah lansaia yang mengalami gangguan sendi ektemitas bawah diantaranya adaalah reumatik dan asam urat.

Berdasarkan berdasarkan hasil penelitian dari 32 orang setelah latihan rentang gerak sendi ektremitas bawah terdapat 17 orang $(53,1 \%)$ dengan resiko jatuh sedang dan 15 orang (46,9\%) dengan resiko jatuh rendah. Hal ini menunjukkan bahwa keseimbangan pada lasia sebelum dan setelah dilakukan latihan rentang gerak sendi ektremitas bawah rata-rata mengalami peningkatan, dimana terdapat 29 responden mengalami peningkatan keseimbangan tubuh.

Menurut penelitian Sudrajat \& Soetardji (2014) yang meneliti tentang efek pemberian latihan keseimbangan dalam mempertahankan kemampuan keseimbangan manula panti Wredha Rindang Asih 1 Ungaran. Disimpulkan bawha berdasarkan hasil penelitian efek pemberian latihan keseimbangan dalam meningkatkan kemampuan keseimbangan manula dapat disimpulkan bahwa, Latihan keseimbangan berefek pada peningkatkan keseimbangan manula Panti Wredha Rindang 1 Asih Ungaran.

Penelitian lain menurut Pongantung, Sampa, \& Melchi (2018), yang meneliti tentang pengaruh range of motion pada ekstremitas bawah terhadap keseimbangan berjalan pada pasien pasca stroke di RS. Stella Maris Makassar. Disimpulkan bahwa terdapat pengaruh range of motion pada ekstremitas bawah terhadap keseimbangan berjalan pada pasien pasca stroke di RS. Stella Maris Makassar

Menurut Potter \& Perry (2010), bahwa latihan rentang gerak (range of motion) yaitu latihan yang dilakukan untuk mempertahankan atau memperbaiki tingkat pengetahuan menggerakkan persendian secara normal dan lengkap untuk meningkatkan massa dan tonus otot. Latihan range of motion mengembangkan kemampuan koordinasi dan aktifitas motorik secara fungsional dan memberikan umpan balik pada saraf sensorik dari kontraksi, sehingga dengan range of motion yang rutin dapat melatih respon reseptor sensorik di seluruh permukaan otot, kulit, kapsul sendi, dan ligament dalam meransang terbentuknya proprioception. Melalui peningkatan latihan pada otot, sendi, dan ligament maka akan meningkatkan sensorimotor yang akan meningkatkan proprioception, dengan meningkatkan proprioception maka akan berpengaruh pada peningkatan keseimbangan.

Menurut Risangdiptya \& Ambarwati (2016), kekuatan otot sangat berhubungan dengan sistem neuromuskuler yaitu seberapa besar kemampuan system saraf mengaktifasi otot untuk melakukan kontraksi. Sehingga semakin banyak serabut otot yang teraktifasi, maka semakin besar pula kekuatan yang dihasilkan otot tersebut. Kekuatan otot dari kaki, lutut serta pinggul harus adekuat untuk mempertahankan keseimbangan tubuh saat adanya tekanan gaya dari luar. Kekuatan otot tersebut berhubungan langsung dengan kemampuan otot untuk melawan gaya gravitasi serta beban eksternal lainnya yang secara terus menerus mempengaruhi posisi tubuh

Berdasarkan hasil penelitian didapat nilai mean 0,833 bernilai negatif yang artinya terdapat kecenderungan peningkatan keseimbangan tubuh lansia setelah latihan rentang gerak sendi ektremitas bawah dengan rata-rata peningkatan 9,656. Menunjukkan bahwa 
terdapat perbedaan rata-rata nilai keseimbangan tubuh dari latihan rentang gerak sendi ektremitas bawah yang dilakukan sebanyak 8 kali dalam waktu 4 hari. Dengan gerakan yang mudah dipahami dan dapat dilakukan dimana saja sehingga latihan rentang gerak ektermitas bawah cukup efektif dilakukan untuk sebagai latihan untuk mempertahankan kekuatan otot dan kelenturan sendi pada lansia sehingga akan meningkatkan dan mempertahankan keseimbangan lansia saat berdiri maupun berjalan.

Beberapa kegiatan yang dilakukan di BPPLU yang berhubungan dengan kesehatan lansia yaitu berupa kontrol kesehatan rutin setiap hari rabu yang dilakukan oleh dokter, peyuluhan kesehatan dan pengobatan gratis. Namun kegiatan yang berhubungan dengan latihan gerak atau olah raga seperti senam lansia, senam jantung sehat dan sebagainya belum dilakukan di BPPLU sehingga dengan kurangnya aktifitas olahraga dan latihan maka akan mempengaruhi kekuatan otot dan kelenturan sendi pada lansia.

Menurut Brown (2014), latihan rentang gerak merupakan latihan pada sendi dengan tujuan meningkatkan rentang gerak sendi, meningkatkan tonus otot dan mencegah kekakuan sendi. Melalui latihan rentang gerak secara aktif pada lanjut usia diharapkan dapat merangsang proprioception secara maksimal. Melalui latihan rentang gerak secara aktif pada lansia diharapkan dapat meningkatkan fungsi pada ekstremitas lanjut usia, baik pada sistem persendian maupun sistem integument. Memaksimalkan fungsi persendian diharapkan dapat meningkatkan penghantaran impuls saraf melalui mechanoresptor.

Hasil uji dua sampel berhubungan (Paired sample t-test) didapat ada pengaruh latihan rentang gerak sendi ektremitas bawah terhadap keseimbangan tubuh lansia di BPPLU Pagar Dewa Provinsi Bengkulu. Hasil ini menunjukkan bahwa latihan rentang gerak ektremitas bahwa dapat digunakan sebagai terapi membetulkan deformitas atau mengembalikan seluruh tubuh ke status kesehatan maksimal. Jika seseorang latihan (excercise), maka akan terjadiperubahan fisiologis dalam sistem tubuh. Dengan demikian dapat disimpulkan denganseringnya seseorang melakukan latihan aktifitas fisik seperti halnya ROM aktif sangat bermanfaat untuk menjaga kebugaran tubuh pada lansia sehingga otot-otot dalam tubuh tetap terjaga elastisitasnya dan sendi dapat melakukan pergerakannya dengan baik, terutama dalam keseimbangan tubuh saat berdiri maupun berjalan.

Menurut penelitian Fitriyansyah, Susanto, \& Rasni (2014) yang meneliti tentang pengaruh latihan rentang gerak ekstremitas bawah terhadap keseimbangan tubuh lansia di Posyandu Alamanda 99 Kelurahan Jember Lor Kabupaten Jember. Disimpulkan bahwa terdapat pengaruh yang signifikan antara latihan rentang gerak ekstremitas bawah terhadap keseimbangan tubuh lansia di Posyandu Alamanda 99 Kelurahan Jember Lor Kabupaten Jember.

Penelitian lain menurut Uda (2016) yang meneliti tentang pengaruh latihan ROM terhadap mobilitas fisik pada lansia di Balai Pelayanan Sosial Tresna Werdha Unit Abiyoso Yogyakarta. Hasil penelitian menunjukkan bahwa terdapat pengaruh yang signifikan antara latihan ROM terhadap mobilitas fisik pada lansia di Balai Pelayanan Sosial Tresna Werdha Unit Abiyoso Yogyakarta.

Menurut Pongantung, Sampa, \& Melchi (2018), latihan gerak secara aktif dapat meningkatkan interaksi antara cortex cerebri, basal ganglia, brain stem dan cerebellum yang berperan penting terhadap perkembangan kemampuan motorik dan pengaturan gerak. Latihan gerak yang melibatkan bagian tubuh yang sakit dan bersifat repetitif akan membantu pasien pasca stroke untuk memperoleh 
kekuatan otot, pergerakan sendi juga memperbaiki keseimbangan.

Menurut Pudjiastuti (2013), latihan rentang gerak mengembangkan kemampuan koordinasi dan aktiftas motorik secara fungsional dan memberikan umpan balik pada saraf sensorik dari kontraksi. Sehingga dengan latihan rentang gerak yang rutin dapat melatih respon reseptor sensorik di seluruh permukaan otot, kulit, kapsul sendi, dan ligament dalam merangsang terbentuknya proprioception. Melalui peningkatan latihan pada otot, sendi, dan ligament maka akan meningkatkan sensorimotor yang akan meningkatkan proprioception, dengan meningkatnya proprioception maka akan berpengaruh pada peningkatan keseimbangan tubuh.

Hasil ini menunjukkan bahwa terapi latihaan rentang gerak ektremitas bawah efektif dilakukan untuk meningkatkan keseimbangan tubuh lansia saat berdiri maupun berjalan. Namun selama ini belum ada kegiatan olah raga atau latihan rutin yang dilakukan oleh BPPLU untuk mempertahankan keseimbangan lansia. Maka diharapkan kepada pihak BPPLU pagar dewa untuk dapat melakukan latihan ROM atau latihan kesehatan jasmani lainnya seperti senam lansia dan senam jantung sehat dengan jadwal rutin yang tetap agar dapat melatih tubuh lansia untuk tetap bugar dan dapat menghambat penurunan fungsi sendi, tulan dan otot sehingga lansia tetap dalam kondisi yang sehat dan prima melalui penambahan kegiatan latihan olah raga fisik

\section{Kesimpulan}

1. Dari 32 orang sebelum latihan rentang gerak sendi ektremitas bawah 29 orang $(90,6 \%)$ dengan resiko jatuh sedang

2. Dari 32 orang setelah latihan rentang gerak sendi ektremitas bawah terdapat 17 orang $(53,1 \%)$ dengan resiko jatuh sedang

3. Ada Pengaruh latihan rentang gerak sendi ektremitas bawah terhadap keseimbangan tubuh lansia di BPPLU Pagar Dewa Provinsi Bengkulu

\section{Daftar Pustaka}

Brown, S. P. (2014). Neuroanatomy and Neuromuscular Control of Movement. Exercise Physiology : Basis of Human Movement in Health and Disease. Philadephia: Lippincott Williams\& Wilkins.

Fitriyansyah, M. A., Susanto, T., \& Rasni, H. (2014). Pengaruh Latihan Rentang Gerak Ekstremitas Bawah Terhadap Keseimbangan Tubuh Lansia Di Posyandu Alamanda 99 Kelurahan Jember Lor Kabupaten Jember. Pustaka Kesehatan, 2 (3) : 523-529.Diunduh dari: Https://Jurnal.Unej.Ac.Id/Index.Ph p/JPK/Article/View/2380.

Kemenkes RI. (2018). Profil Kesehatan Indonesia 2017. Jakarta : Kemenkes RI.

Lestari, A. \& Hartati, N. (2016). Hubungan Self Efficacy dengan Subjective Well Being pada Lansia Yang Tinggal di Rumahnya Sendiri. Jurnal RAP UNP, 7 (1) : 12-23.Diunduh dari :http://ejournal.unp.ac.id/index.php /psikologi /article/view/6603.

Lueckenotte. (2009). Gerontologic Nursing. United States of Amerika: Mosby.

Maryam,. S. R. (2011). Mengenal Usia Lanjut dan Perawatannya. Jakarta : Salemba Medika.

Pongantung, A, Sampa, S. A., \& Melchi, S. D. (2018). Pengaruh Range Of Motion pada Ekstremitas Bawah terhadap Keseimbangan Berjalan pada Pasien Pasca Stroke di RS. Stella Maris Makassar. Jurnal Ilmiah Kesehatan Diagnosis, 12 (3) : 271-276, Diunduh dari: http://ejournal.stikesnh.ac.id/index. php/jikd/article/download/319/203/

Potter \& Perry. (2010). Fundamental Keperawatan. Jakarta : Salemba Medika. 
Pudjiastuti, S. S. (2013). Fisioterapi pada Lansia. Jakarta : EGC.

Ramlis, R. (2018). Faktor-Faktor yang Berhubungan dengan Risiko Jatuh Pada Lansia di BPPLU Kota Bengkulu Tahun 2017. JNPH, 6 (1) : 63-67. Diunduh dari Error! Hyperlink reference not valid.

Risangdiptya, G., \& Ambarwati, E. (2016). Perbedaan antara Keseimbangan Tubuh Sebelum dan Sesudah Senam Pilates pada Wanita Usia Muda. Diponegoro Medical Journal (Jurnal Kedokteran Diponegoro), 5 (4) : 911-916. Diunduh dari https://ejournal3.undip.ac.id/ index.php/medico/article/view/144 52.

Stocklager, J. (2008). Buku Saku Asuhan Keperawatan Geriatrik Edisi 2. Jakarta: EGC.

Sudrajat, W. A., \& Soetardji. (2014). Efek Pemberian Latihan Keseimbangan dalam Mempertahankan Kemampuan Keseimbangan Manula Panti Wredha Rindang Asih 1 Ungaran. Journal of Sport Sciences and Fitness, 3 (1) : 4954. Diunduh dari https://journal.unnes.ac.id/sju/inde X.php/jssf /article/view/6211.

Susilo, W., Limyati, Y., \& Gunawan, D. (2017). The Risk of Falling in Elderly Increased with Age Growth and Unaffected by Gender. Journal of Medicine and Health, 1 (6) : 568-574. Diunduh dari : https://www.researchgate.net/publi cation/322825298_The Risk_of_F alling_in_Elderly_Increased_with_ Age_Growth_and_Unaffected_by Gender.

Uda, H. D. S. Muflih, \& Amigo, T. A. E. (2016). Latihan Range of Motion Berpengaruh terhadap Mobilitas Fisik pada Lansia di Balai Pelayanan Sosial Tresna Werdha. Unit Abiyoso Yogyakarta. JNKI, 4 (3) : 169-177. Diunduh dari : https://ejournal.almaata.ac.id/index .php/JNKI/article/view/358. 